九州大学学術情報リポジトリ

Kyushu University Institutional Repository

\title{
Dynamic recrystallization and recovery during high-pressure torsion : Experimental evidence by torque measurement using ring specimens
}

\section{Edalati, Kaveh}

Department of Materials Science and Engineering, Faculty of Engineering, Kyushu University I WPI, International Institute for Carbon-Neutral Energy Research (WPI-I2CNER), Kyushu University

Horita, Zenj i

Department of Materials Science and Engineering, Faculty of Engineering, Kyushu University I WPI, International Institute for Carbon-Neutral Energy Research (WPI-I2CNER), Kyushu University

Furuta, Tadahiko

Frontier Research Center, Toyota Central R\&D Laboratories Inc.

Kuramoto, Shigeru

Frontier Research Center, Toyota Central R\&D Laboratories Inc.

http://hdl. handle. net/2324/26379

出版情報: Materials Science and Engineering：A. 559, pp.506-509，2013-01-01. Elsevier バージョン：

権利関係: (C) 2012 Elsevier B.V. 


\title{
Dynamic recrystallization and recovery during high-pressure torsion: Experimental evidence by torque measurement using ring specimens
}

\author{
Kaveh Edalati $^{\text {a,b, } * \text {, Zenji Horita }}{ }^{\text {a,b }}$, Tadahiko Furuta ${ }^{\text {c, Shigeru Kuramoto }}{ }^{\text {c }}$
}

${ }^{a}$ Department of Materials Science and Engineering, Faculty of Engineering, Kyushu University, Fukuoka 819-0395, Japan

${ }^{b}$ WPI, International Institute for Carbon-Neutral Energy Research (WPI-I2CNER), Kyushu University, Fukuoka 819-0395, Japan

${ }^{\mathrm{c}}$ Frontier Research Center, Toyota Central R\&D Laboratories Inc., Nagakute, Aichi 480-1192, Japan

\begin{abstract}
Several pure metals exhibit softening when imparting large strains at room temperature. This study investigates the nature of this strain softening. Torque measurements during high-pressure torsion using ring specimens, which appear to be more suitable than disk specimens for the evaluation of the strain response on the in situ flow stress, suggest that the softening in aluminum occurs mainly by dynamic recrystallization and recovery, whereas no appreciable dynamic softening occurs in copper. The softening in aluminum is associated with decreasing the dislocation density and increasing the grain size and missorientation angles, whereas copper exhibits ultrafine grains of higher dislocation density and few nanotwins. A significant static recrystallization is detected in HPT-processed pure copper by argon irradiation during ion milling.
\end{abstract}

Keywords: Severe plastic deformation (SPD) Aluminum Copper Stacking fault energy Homologous temperature Twin.

* Corresponding author at: Department of Materials Science and Engineering, Faculty of Engineering, Kyushu University, Fukuoka 819-0395, Japan.

Tel./fax: +81928022992.

E-mail address: Kaveh.edalati@zaiko6.zaiko.kyushu-u.ac.jp (K. Edalati). 


\section{Introduction}

High-pressure torsion (HPT) is a typical process of severe plastic deformation (SPD) [1,2], which is mainly used for grain refinement [3-5] and phase transformation [6,7]. Application of HPT has shown that, in many metals and alloys, a steady level of hardness is reached following the initial increase with straining [2-4]. However, in high-purity Al, the hardness initially increases with increasing strain and, after reaching a maximum, decreases to a constant level [8-12]. This behavior was also reported in pure Al processed by equal-channel angular pressing (ECAP) [13-15], but was not observed in commercially-pure Al when processed by HPT [16] and ECAP [17].

A hardness behavior similar to pure Al was reported in metals with low melting temperatures such as $\mathrm{Zn} \mathrm{[18]} \mathrm{and} \mathrm{Mg}$ [19]. Several papers reported a hardness peak in pure $\mathrm{Cu}$ processed by HPT [20,21] and ECAP [22-24], whereas the hardness peak for Cu was not reported in several other papers using HPT [25-28] and ECAP [29-32]. The current authors showed that $\mathrm{Cu}$ exhibits a hardness behavior similar to $\mathrm{Al}$ after HPT at a homologous temperature corresponding to room temperature of $\mathrm{Al}$ and successively keeping the samples at the same homologous temperature after HPT [33].

The unusual softening of pure $\mathrm{Cu}$ at large strains was first attributed to dynamic recrystallization [22] or recovery [23]. However, Schafler [21] and Wetscher et al. [34] found that no peak appears in $\mathrm{Cu}$ when in-situ flow stress of a disk specimen is examined during HPT by torque measurements. Detailed measurements showed that a static softening in $\mathrm{Cu}$ results in a hardness maximum, a hardness minimum followed by a steady state [35]. Kilmametov et al. [36] confirmed the occurrence of a static relaxation in Cu after HPT using high-energy synchrotron light. Takayama et al. [37] showed the significance of static recrystallization in ultrafine-grained $\mathrm{Cu}$.

The softening of pure $\mathrm{Al}$ at large strains was attributed to its large stacking fault energy (SFE) and easy dynamic recovery [8] or to its high homologous temperature and easy recrystallization [33]. Kuo and Rigney [38] confirmed the occurrence of the recrystallization in pure Al severely deformed by sliding. A recent report indicated that the contribution of dynamic softening (recrystallization and recovery) becomes more significant as the homologous temperature and SFE increase [18]. Earlier papers reported the occurrence of a torque peak and a strain softening in $\mathrm{Al}$ disks deformed by large torsional strains at elevated temperatures $\left(\mathrm{T}>300{ }^{\circ} \mathrm{C}\right)$ [39]. However, Bachmaier et al. [40] examined the in-situ flow stress of several disk specimens of pure $\mathrm{Al}$ and $\mathrm{Al}$ alloys by torque measurements at room temperature, but they reported no torque peak during the process. Despite these reports, there has been no direct evidence to show whether the softening in $\mathrm{Al}$ and $\mathrm{Cu}$ at large strains and room temperature occurs during (dynamic) or after (static) the process.

In this study, pure $\mathrm{Al}$ and $\mathrm{Cu}$ are processed by HPT and any possible occurrence of softening is examined with respect to strain during and after HPT by torque and microhardness measurements including transmission electron microscopy (TEM).

\section{Experimental Materials and Procedures}

The experiments were conducted using pure (99.99\%) Al and Cu sheets, of which purities 
match the ones used in the earlier reports for $\mathrm{Al}[8-12,18,33]$ and $\mathrm{Cu}[18,26,35]$. The sheets were cut to disks with $10 \mathrm{~mm}$ diameter and rings with inner and outer diameters of $14 \mathrm{~mm}$ and $20 \mathrm{~mm}$ with $0.8 \mathrm{~mm}$ thickness. The $\mathrm{Al}$ and $\mathrm{Cu}$ specimens were annealed before $\mathrm{HPT}$ at $773 \mathrm{~K}$ and $873 \mathrm{~K}$ for 1 hour, respectively. The HPT was conducted on disks and rings using facilities illustrated in Refs. [9,26], for 0.25-5 turns at room temperature under a pressure of $1 \mathrm{GPa}$. The rotation speeds were selected as 0.2 and $0.5 \mathrm{rpm}$ for the rings and disks, respectively, to reduce the temperature rise during HPT. It should be noted that, because the applied pressure of $1 \mathrm{GPa}$ is rather low, a slippage between the sample and anvil may occur during HPT, especially for the Cu disks. However, the fraction of slippage, $s$, is not very significant $(s<0.25)$ [41].

The disks and rings were first evaluated by torque measurements during HPT using strain gauges placed on the upper anvil as described in Ref. [42]. To examine the reproducibility, each torque measurement was repeated several times on different samples processed at the same HPT conditions. Second, the samples were polished to a mirror-like surface and Vickers microhardness was measured along the radii at 4 different radial directions with an applied load of $50 \mathrm{~g}$ for $\mathrm{Al}$ and $200 \mathrm{~g}$ for $\mathrm{Cu}$. Third, 3mm disks were cut from $3.5 \mathrm{~mm}$ away from the disk center and thinned with an electro-chemical polisher using the solutions given in Ref. [18] and further examined by TEM.

\section{Results and Discussion}

The hardness values are plotted against the shear strain, $\gamma(\gamma=2 \pi r N / h, r$ : distance from disk or ring center, $N$ : number of turns, $h$ : thickness of disk or ring [1]), in Fig. 1 for (a) $\mathrm{Al}$ and (b) $\mathrm{Cu}$. The hardness of $\mathrm{Al}$ initially increases to a maximum, decreases with a further increase in $\gamma$ and reaches a steady-state level. For $\mathrm{Cu}$, the hardness increases with increasing $\gamma$ but levels off without taking a peak.

TEM micrographs and corresponding selected-area electron diffraction (SAED) patterns are shown in Fig. 2 for $\mathrm{Al}$ where (a-c) were taken from a disk after 0.25 turns which correspond to the hardness maximum, and (d) was taken from a disk after 5 turns which corresponds to the steady state. Dark-field and bright-field images in (a) and (b) shows that grains are separated by low angles of missorientations with an average grain size of $\sim 0.8 \mu \mathrm{m}$. Examination of the microstructure using a higher magnification in (c) reveals that dislocations are visible within many grains and especially near the grain boundaries. The grain size at the steady state is fairly increased to $\sim 1.9 \mu \mathrm{m}$ and grains are separated by high angles of missorientations in (d). Earlier experiments using electron back-scatter diffraction analysis confirmed the presence of low-angle grain boundaries at the hardness peak and of high-angle grain boundaries at the steady state [10]. Although grains containing high dislocation density are locally visible within the microstructures as marked $\mathbf{A}$, few dislocations are visible within most of the grains with the grain boundaries well-defined in (d). It is noted that the grains with high-angle grain boundaries which have substructures but few dislocation within them as marked $\mathbf{B}$ in (d) are typical of grains after dynamic recrystallization or recovery [43]. 

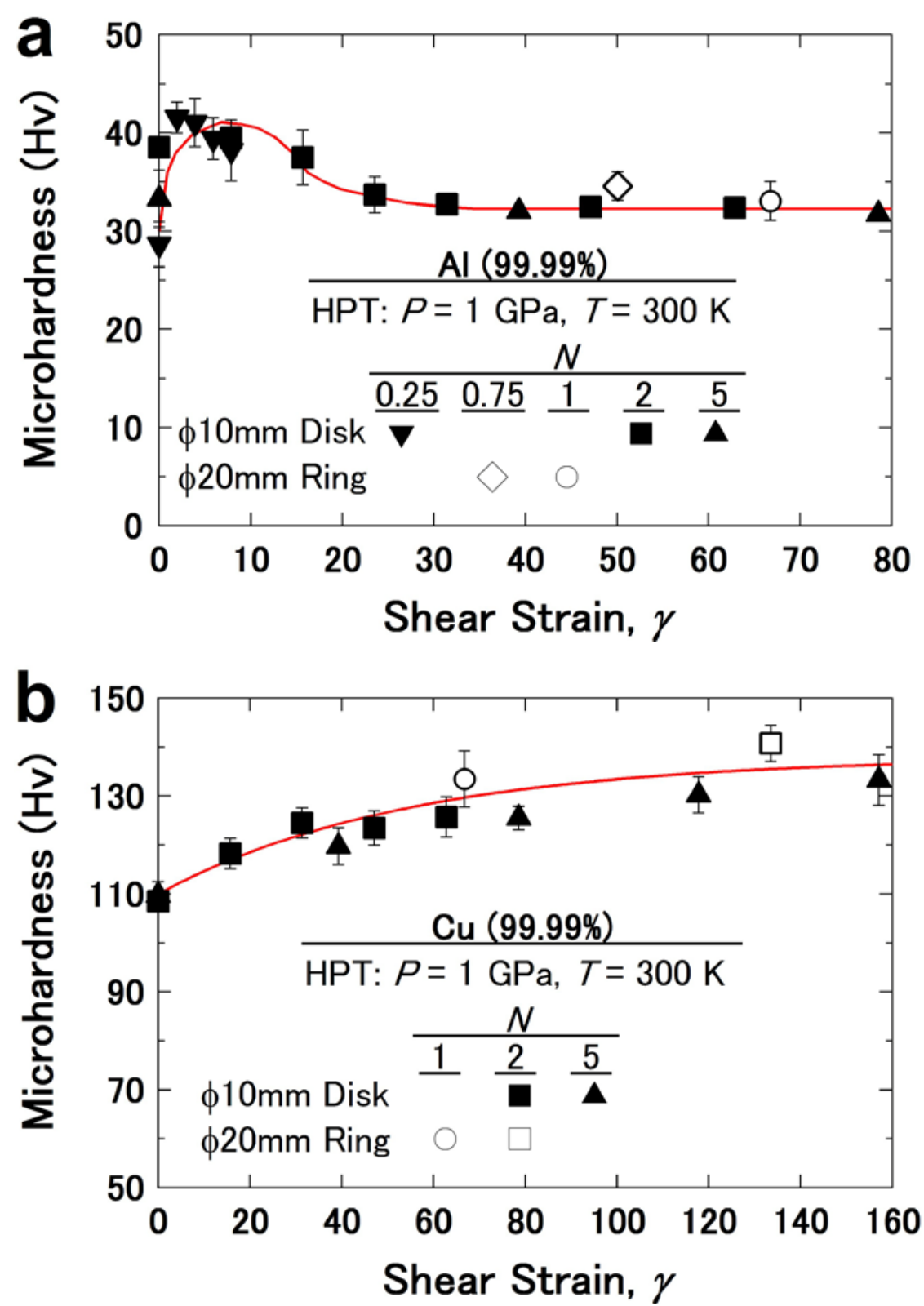

Figure 1. Microhardness plotted against shear strain for (a) $\mathrm{Al}$ and (b) $\mathrm{Cu}$ disks and rings processed after various turns.

TEM micrographs are shown in Fig. 3 for $\mathrm{Cu}$ after processing a disk for 5 turns which correspond to the steady state. Bright-field image in (a) shows that most grains contain many dislocations with ill-defined grain boundaries with an average grain size of $\sim 0.4 \mu \mathrm{m}$. The ring pattern recorded from an area of $\sim 6.2 \mu \mathrm{m}$ diameter using SAED analysis in (a) also indicates that the grains are small and separated by high angles of misorientations. Examination of the microstructure in a higher magnification using weak beam technique, as shown in (b), reveals that several dislocations (10-30) are visible within interior of many grains. Although the dislocation density in $\mathrm{Cu}$ is clearly higher than that in $\mathrm{Al}$, the dislocation density appears to be less than the estimated values by X-ray diffraction analyses [21] as all dislocations may not be detected using the weak beam technique. The dislocation density was estimated $1.8 \times 10^{14} \mathrm{~m}^{-2}$ in SPD-processed Al [44] and $4.4 \times 10^{15} \mathrm{~m}^{-2}$ in SPD-processed $\mathrm{Cu}$ [21] by X-ray diffraction analyses. Examination of lattice 
images in (c) and (d) clearly shows that the $\{111\}<110>$ edge dislocation are present in the interior of many grains. Close examination of the microstructure indicates that the deformation nanotwins are also visible within a few grains as in (e). The presence of grains with a few dislocations within the grains as marked $\mathbf{C}$ in (a) suggests that dynamic recrystallization has taken place partially in $\mathrm{Cu}$ [26]. It should be noted that the HPT-processed $\mathrm{Cu}$ may exhibit a significant static softening by slight heating or irradiation. An example is shown in (f) when the sample after TEM for an image in (a-e) was now subjected to ion milling for 15 min using Ar ions with $4.5 \mathrm{keV}$ energy for surface cleaning and repeated observation. Many large grains with large twins but no dislocations and no substructures appear as marked $\mathbf{D}$ in (f), which resemble a typical microstructural feature after static recrystallization [35]. Since this kind of large grains was never found after electropolishing, it turns out that a significant static recrystallization occurs by Ar irradiation during ion milling. It should be noted that the application of ion milling using Ar ions with a lower energy as $3 \mathrm{keV}$ for 60 min also resulted in an appreciable dynamic recovery and smoothening the grain boundaries. These observations lead to an important suggestion that the ultrafine-grained materials should be handled very carefully before the evaluation.

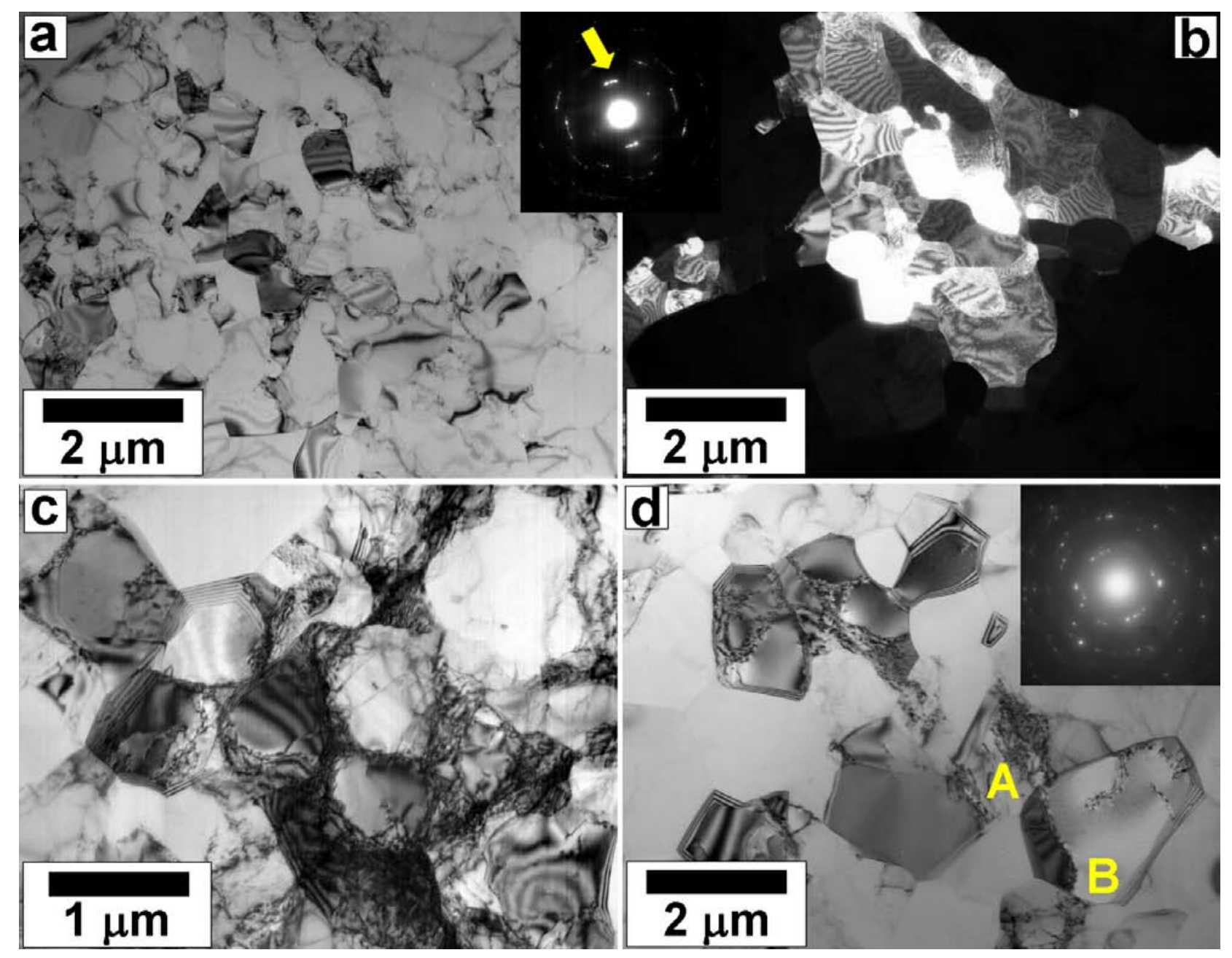

Figure 2. TEM micrographs and SAED patterns for Al disks after (a-c) 0.25 turns and (d) 10 turns, where (b) is dark-field image of (a) taken with diffracted beams indicated by arrow in SAED pattern. 

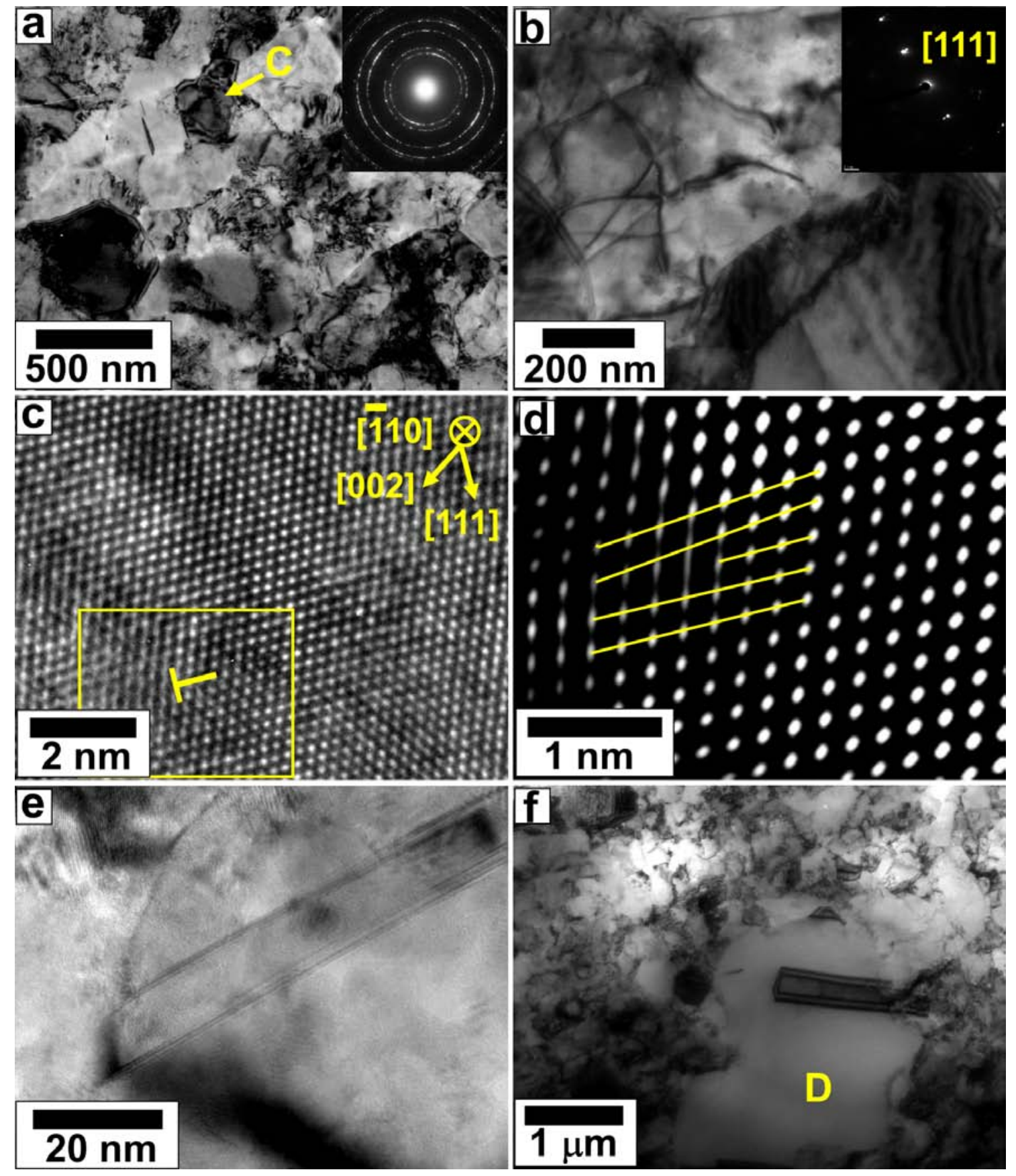

Figure 3. TEM micrograph of Cu disk after 5 turns. (a) bright-field image and corresponding SAED pattern, (b) bright-field image taken by weak beam technique and corresponding SAED pattern, (c) lattice image with edge dislocation marked $\mathrm{T}$, (d) reconstructed lattice images of square region of (c) processed by inverse fast Furrier transform from $\{111\}$ beams, (e) high resolution image of nanotwin, (f) bright-field image after further processing of TEM foil by ion milling at $4.5 \mathrm{keV}, 30$ $\mu \mathrm{A}$ for $15 \mathrm{~min}$.

The torque-strain curves are shown in Fig. 4 for (a) $\mathrm{Al}$ and (b) $\mathrm{Cu}$ using both disks and rings. The average shear strain for $N$ turns in HPT was calculated as $\gamma=27 N(r=3.5 \mathrm{~mm}, h=0.8$ $\mathrm{mm})$ for the disks and $\gamma=67 \mathrm{~N}(r=8.5 \mathrm{~mm}, h=0.8 \mathrm{~mm})$ for the rings. Figure 4 shows that the torque for the disks in both $\mathrm{Al}$ and $\mathrm{Cu}$ increases with increasing $\gamma$ at an early stage of straining but 
levels off with further straining without taking a peak. Although this behavior is the same for the ring of $\mathrm{Cu}$, it is different for the ring of $\mathrm{Al}$ where the torque exhibits a peak with straining. Considering such differences in the torque behavior, the disk sample may not be sensitive enough for the evaluation of the strain response on the flow stress. This is because there is a significant strain gradient in the disks, and thus, the measured torque does not represent the outcome along a single straining path but due to combined straining paths from the center to the edge of the disk. Therefore, a peak may not be detected for the disk even if a softening occurs. For instance, the difference between $\gamma$ at $r=0.1 \mathrm{~mm}$ (close to disk center) and $r=5 \mathrm{~mm}$ (disk periphery) is as high as $5000 \%$. However, the difference between $\gamma$ in the inner $(r=7 \mathrm{~mm})$ and outer $(r=10 \mathrm{~mm})$ periphery of the rings is only 30\%. It is then apparent from Fig. 4 that a torque peak appears in Al but no peak appears in $\mathrm{Cu}$, indicating that a dynamic softening must have taken place during HPT processing of $\mathrm{Al}$. However, a comparision between the magnitude of the torque and hardness peaks a suggest that the contribution of static softening in the hardness decrease of HPT-processed Al can not be negated as disussed in [18].
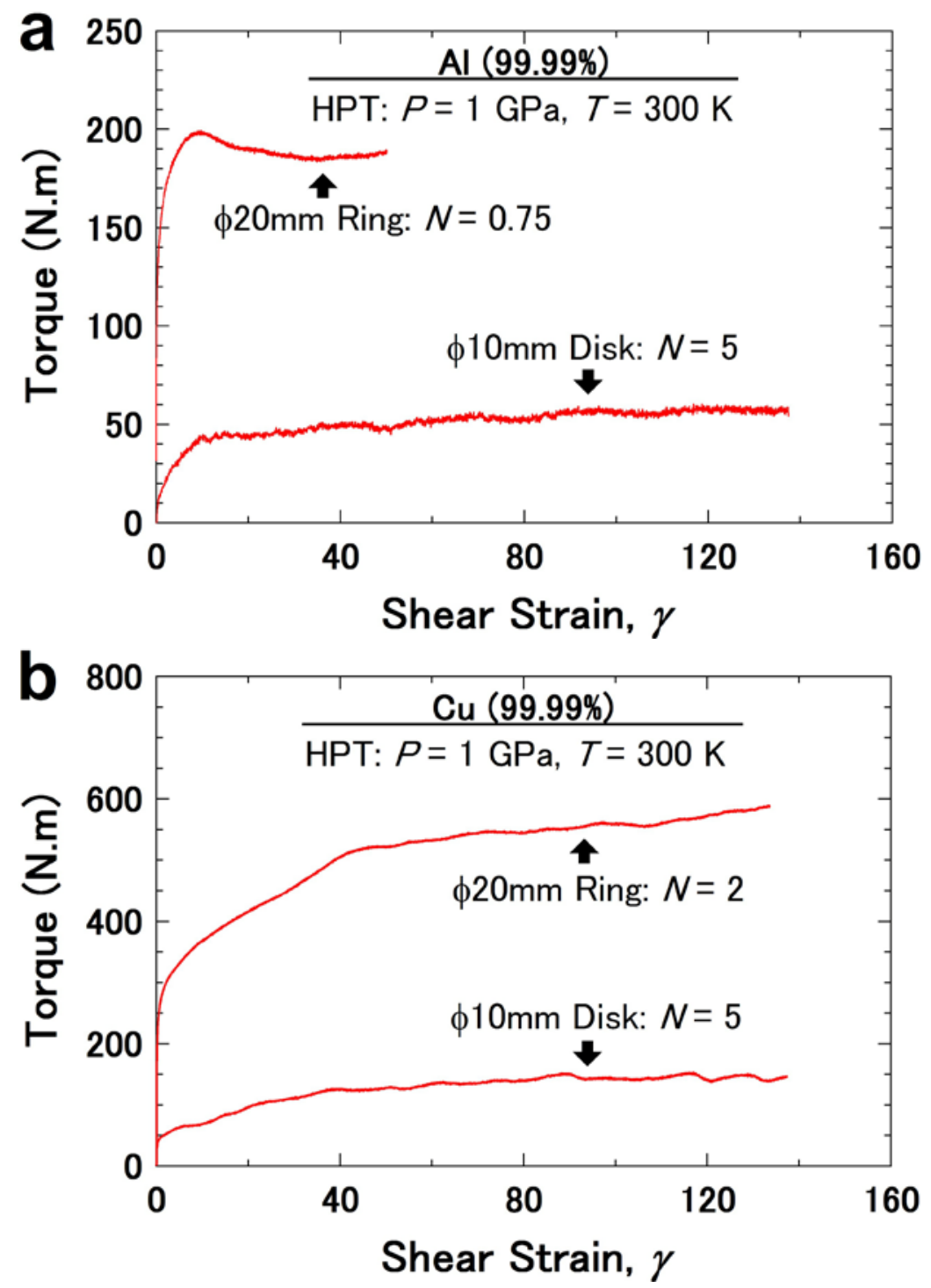

Figure 4. Torque plotted against shear strain for (a) Al and (b) Cu using disks processed for 5 turns and rings processed for 0.75 and 2 turns. 
A question naturally arises: why a dynamic softening occurs in pure $\mathrm{Al}$ at room temperature but no appreciable dynamic softening occurs in pure $\mathrm{Cu}$. The differences can be attributed to the dislocation mobility affected by (i) crystal structure, (ii) purity, (iii) homologous temperature, and (iv) SFE. For the crystal structure, $\mathrm{Al}$ and $\mathrm{Cu}$ are both based on fcc so that this should not be the reason for the difference. The effect of purity should be neglected because the purity level is as high as $99.99 \%$ in both metals. However, there are appreciable differences in the homologous temperature and the SFE between the two metals: the homologous temperature is 0.32 for $\mathrm{Al}$ and 0.22 for $\mathrm{Cu}$ and the SFE is $166 \mathrm{~mJ} / \mathrm{m}^{2}$ for $\mathrm{Al}$ and $36 \mathrm{~mJ} / \mathrm{m}^{2}$ for $\mathrm{Cu}$ [33]. On the one hand, the dislocations cross-slip and climb become easier when the homologous temperature is higher. On the other hand, the larger SFE promotes faster cross-slip and increases the dislocation mobility. Therefore, the dislocations moves easier and thus the microstructure and resultant softening evolve much faster in $\mathrm{Al}$ than in $\mathrm{Cu}$. This fast evolution even proceeds dynamically during HPT, thus creating a dynamic softening in the torque measurement. It should be noted that the smaller grain size in $\mathrm{Cu}$ must be due to its low homologous temperature [18] and the presence of deformation nanotwins in $\mathrm{Cu}$, although their density is low, must be due to the low SFE [45].

\section{Conclusions}

1. The current study introduces the torque measurements during HPT using ring specimens as a unique tool to investigate the dynamic behavior of materials during severe plastic deformation.

2. Torque measurements presented a direct evidence showing that the softening of pure $\mathrm{Al}$ at large strains is mainly due to dynamic recrystallization and recovery.

3. Although the presence of a few grains with less dislocation suggested that dynamic softening takes place partially in pure $\mathrm{Cu}$, no appreciable dynamic softening in pure $\mathrm{Cu}$ was detected within the sensitivity limit of torque measurements.

4. Severely-deformed pure $\mathrm{Cu}$ exhibited a high sensitivity to static softening and a significant static recrystallization was detected in HPT-processed pure Cu by Ar irradiation during ion milling.

\section{ACKNOWLEDGEMENTS}

One of the authors (KE) thanks the Japan Society for Promotion of Science (JSPS) for a postdoctoral scholarship. This work was supported in part by the Light Metals Educational Foundation of Japan, in part by a Grant-in-Aid for Scientific Research from the MEXT, Japan, in Innovative Areas "Bulk Nanostructured Metals" and in part by Kyushu University Interdisciplinary Programs in Education and Projects in Research Development (P\&P).

\section{References}

[1] R.Z. Valiev, Y. Estrin, Z. Horita, T.G. Langdon, M.J. Zehetbauer, Y.T. Zhu, JOM 58(4) (2006) 33-39.

[2] R.Z. Valiev, R.K. Islamgaliev, I.V. Alexandrov, Prog. Mater. Sci. 45 (2000) 103-189.

[3] A.P. Zhilyaev, T.G. Langdon, Prog. Mater. Sci. 53 (2008) 893-979.

[4] R. Pippan, S. Scheriau, A. Taylor, M. Hafok, A. Hohenwarter, A. Bachmaier, Annu. Rev. Mater. Res. 40 (2010) 319-343.

[5] V.V. Popov, E.N. Popova, E.N. Stolbovskiy, V.P. Pilyugin, Mater. Sci. Eng. A 528 (2011) 
1491-1496.

[6] Y. Todaka, J. Sasaki, T. Moto, M. Umemoto, Scripta Mater. 59 (2008) 615-618.

[7] B.B. Straumal, A.S. Gornakova, A.A. Mazilkin, O.B. Fabrichnaya, M.J. Kriegel, B. Baretzky, J.Z. Jiang, S.V. Dobatkin, Mater. Lett. 81 (2012) 225-228.

[8] C. Xu, Z. Horita, T.G. Langdon, Acta Mater. 55 (2007) 203-212.

[9] Y. Harai, Y. Ito, Z. Horita, Scripta Mater. 58 (2008) 469-472.

[10] Y. Ito, Z. Horita, Mater. Sci. Eng. A 503 (2009) 32-36.

[11] M. Kawasaki, B. Ahn, T.G. Langdon, J. Mater. Sci. 45 (2010) 4583-4593.

[12] M. Kawasaki, R.B. Figueiredo, T.G. Langdon, Acta Mater. 59 (2011) 308-316.

[13] J.C. Lee, J.Y. Suh, J.P. Ahn, Metall. Mater. Trans. A 34 (2003) 625-632.

[14] Z. Horita, K. Kishikawa, K. Kimura, K. Tatsumi, T.G. Langdon, Mater. Sci. Forum 558-559 (2007) 1273-1278.

[15] T. Inoue, Z. Horita, H. Somekawa, K. Ogawa, Acta Mater. 56 (2008) 6291-6303

[16] A.P. Zhilyaev, T.R. McNelley, T.G. Langdon, J. Mater. Sci. 42 (2007) 1517-1528.

[17] M. Reihanian, R. Ebrahimi, N. Tsuji, M.M. Moshksar, Mater. Sci. Eng. A 473 (2008) 189-194.

[18] K. Edalati, Z. Horita, Mater. Sci. Eng. A 528 (2011) 7514-7523.

[19] K. Edalati, A. Yamamoto, Z. Horita, T. Ishihara, Scripta Mater. 64 (2011) 880-883.

[20] A. Dubravina, M.J. Zehetbauer, E. Schafler, I.V. Alexandrov, Mater. Sci. Eng. A 387-389 (2004) 817-821.

[21] E. Schafler, Scripta Mater. 62 (2010) 423-426.

[22] M.H. Shih, C.Y. Yu, P.W. Kao, C.P. Chang, Scripta Mater. 45 (2001) 793-799.

[23] F.H. Dalla Torre, E.V. Pereloma, C.H.J. Davies, Acta Mater. 54 (2006) 1135-1146.

[24] W. Wei, K.X. Wei, G.J. Fan, Acta Mater. 56 (2008) 4771-4779.

[25] T. Hebesberger, H.P. Stuwe, A. Vorhauer, F. Wetscher, R. Pippan, Acta Mater. 53 (2005) 393-402.

[26] K. Edalati, T. Fujioka, Z. Horita, Mater. Sci. Eng. A 497 (2008) 168-173.

[27] X.H. An, S.D. Wu, Z.F. Zhang, R.B. Figueiredo, N. Gao, T.G. Langdon, Scripta Mater. 63 (2010) 560-563.

[28] J. Cizek, M. Janecek, O. Srba, R. Kuzel, Z. Barnovska, I. Prochazka, S. Dobatkin, Acta Mater. 59 (2011) 2322-2329.

[29] S. Komura, Z. Horita, M. Nemoto, T.G. Langdon, J. Mater. Res. 14 (1999) 4044-4050.

[30] H.S. Kim, Mater. Sci. Eng. A 328 (2002) 317-323.

[31] A. Mishra, B.K. Kad, F. Gregori, M.A. Meyers, Acta Mater. 55 (2007) 13-28.

[32] R.J. Hellmig, M. Janecek, B. Hadzima, O.V. Gendelman, M. Shapiro, X. Molodova, A. Springer, Y. Estrin, Mater. Trans. 49 (2008) 31-37.

[33] K. Edalati, Y. Ito, K. Suehiro, Z. Horita, Int. J. Mater. Res. 100 (2009) 1668-1673.

[34] F. Wetscher, A. Vorhauer, R. Pippan, Mater. Sci. Eng. A 410-411 (2005) 213-216.

[35] K. Edalati, K. Imamura, T. Kiss, Z. Horita, Mater. Trans. 53 (2012) 123-127.

[36] A.R. Kilmametov, G. Vaughan, A.R. Yavari, A. LeMoulec, W.J. Botta, R.Z. Valiev, Mater. Sci. Eng. A 503 (2009) 10-13.

[37] A. Takayama, X. Yang, H. Miura, T. Sakai, Mater. Sci. Eng. A 478 (2008) 221-228.

[38] S.M. Kuo, D.A. Rigney, Mater. Sci. Eng. A 157 (1992) 131-143.

[39] M.E. Kassner, M.M. Myshlyaev, H.J. McQueen, Mater. Sci. Eng. A 108 (1989) 45-61.

[40] A. Bachmaier, M. Hafok, R. Pippan, Mater. Trans. 51 (2010) 8-13.

[41] K Edalati, Z. Horita, T.G. Langdon, Scripta Mater. 60 (2009) 9-12.

[42] T. Furuta, S. Kuramoto, N. Nagasako, Z. Horita, Mater. Sci. Forum 706-709 (2012) 1769-1774.

[43] H.J. McQueen, W. Blum, Mater. Sci. Eng. A 290 (2000) 95-107.

[44] J. Cubicza, N.Q. Chinh, T. Csanadi, T.G. Langdon, T. Ungar, Mater. Sci. Eng. A 462 (2007) 86-90.

[45] Y.T. Zhu, X.Z. Liao, X.L. Wu, Prog. Mater. Sci. 57 (2012) 1-62. 